Bolscher-Niehuis, M.J.T van het, Ouden, M.E.M. den, Vocht, H.M. de, Francke, A.L. Effects of self-management support programmes on activities of daily living of older adults: a systematic review. International Journal of Nursing Studies: 2016, 61(9), 230-247

\begin{tabular}{|l|l|}
\hline $\begin{array}{l}\text { Postprint } \\
\text { Version }\end{array}$ & 1.0 \\
\hline Journal website & http://dx.doi.org/10.1016/i.ijnurstu.2016.06.014 \\
\hline Pubmed link & http://www.ncbi.nlm.nih.gov/pubmed/27400029 \\
\hline DOI & $10.1016 /$ j.jnurstu.2016.06.014 \\
\hline
\end{tabular}

This is a NIVEL certified Post Print, more info at http://www.nivel.eu

\title{
Effects of self-management support programmes on activities of daily living of older adults: A systematic review
}

\author{
MARIAN J.T. VAN HET BOLSCHER-NIEHUIS ${ }^{A,}$, MARJOLEIN E.M. DEN OUdEN ${ }^{\mathrm{A}}$, HILDE M. DE \\ VOCHT $^{\mathrm{A}}$, ANNEKE L. FRANCKE ${ }^{\mathrm{B}, \mathrm{C}}$ \\ ${ }^{a}$ Centre for Nursing Research, Saxion University of Applied Sciences, Deventer/Enschede, \\ P.O. Box 70.000, 7500 KB Enschede, The Netherlands \\ b The Netherlands Institute for Health Services Research (NIVEL), P.O. Box 1568, 3500 BN \\ Utrecht, The Netherlands \\ ${ }^{c}$ Department of Public and Occupational Health, EMGO Institute for Health and Care \\ Research (EMGO+) of the VU University Medical Centre Amsterdam, P.O. Box 7057, 1007 \\ MB Amsterdam, The Netherlands
}

\begin{abstract}
Background:The ability of older adults to carry out activities of daily living and to adapt and to manage their own life decreases due to deterioration of their physical and cognitive condition. Nurses and other health care professionals should support the self-management ability of older adults to prevent activities of daily living dependence and increase the ability to adapt and to self-manage the consequences of living with a chronic condition.

Objective: To gain insight into the evidence of the effects of self-management support programmes on the activities of daily living of older adults living at home.

Design: A systematic literature review of original research publications.

Data sources: Searches were performed in PubMed, CINAHL, PsychInfo, EMBASE and the Cochrane Central Register of Controlled Trials (in February 2016). No limitations were applied regarding date of publication, language or country.

Review methods: Publications were eligible for this review on condition that they described a self-management support programme directed at adults of on average 65 years or older, and living in the community; used a randomized control group design; and presented information about the effects on activities of daily living. The methodological quality of the included studies was independently assessed by the authors using the quality criteria for reviews of the Cochrane Effective Practice and Organisation of Care Review Group. A best evidence synthesis was performed using guidelines provided by the Cochrane Collaboration Back Review Group.
\end{abstract}


Results: A total of 6246 potentially relevant references were found. After screening the references, 12 studies with a randomized controlled trial design were included. The methodological assessment of the 12 studies indicated variations in the risk of bias from low $(n=1)$ to unclear $(n=3)$ and high $(n=8)$. Although there was considerable variation in study population, intervention characteristics and measurement instruments used, most studies $(n=11)$ showed effects of self-management support programmes on the activities of daily living of older adults.

Conclusions:There is a moderate level of evidence that self-management support programmes with a multi-component structure, containing diseasespecific information, education of knowledge and skills and, in particular, individually tailored coaching, improve the activities of daily living of older adults.

Further research is required to gain insight into the most appropriate context and approach of self-management support interventions targeting activities of daily living of older adults living in the community.

\section{What is already known about the topic?}

- $\quad$ Self-management support programmes have proven to be useful and beneficial when it comes to health related quality of life, self-efficacy, disease specific self-care behaviour and cost effectiveness.

\section{What this paper adds}

- This systematic review demonstrates that self-management support programmes can contribute to the activities of daily living of older adults living in the community.

- The self-management support programmes had a multi-component structure, focussing on disease-specific information, education of knowledge and skills and coaching of health behaviour changes or problem solving.

- In particular, self-management support programmes using a personalized plan tailored to the participants' individual problems and goals resulted in improvements in physical functioning and the activities of daily living of older adults.

\section{INTRODUCTION}

In the years to come, health care professionals will be challenged to provide quality health care for increasing numbers of older and frail people with limited health care resources. For many elderly people, life at an advanced age is pleasant, but most elderly people are also confronted with long-term disabilities, chronic illnesses and other health problems that impact the ability to perform activities of daily living (CSO et al., 2012). Activities of daily living are defined as routine activities that people tend to do every day and are performed to live independently. Activities of daily living consist of basic activities of daily living, such as eating, bathing, dressing, toileting, transferring (walking) and continence (Katz et al., 1963), and instrumental activities of daily living, like the ability to use the telephone, shopping, 
Bolscher-Niehuis, M.J.T van het, Ouden, M.E.M. den, Vocht, H.M. de, Francke, A.L. Effects of self-management support programmes on activities of daily living of older adults: a systematic review. International Journal of Nursing Studies: 2016, 61(9), 230-247

food preparation, housekeeping, laundry, mode of transportation, responsibility for own medication and the ability to handle finances (Lawton and Brody, 1969). Frail people, in particular, are at high risk of decreased mobility and dependence in activities of daily living (Fried et al., 2001). Effective interventions aimed at preventing activities of daily living disability may diminish the burden that frailty places on elderly people, care providers and the health care system as a whole (Vermeulen et al., 2011). Nurses and other health care professionals have a critical role in the implementation of future preventive treatment interventions for frailty (Rochat et al., 2010). In addition, active involvement of the older adults is a key component, which is in line with the principles of care according to 'selfmanagement' (Barlow et al., 2002 and Pulvirenti et al., 2014). Self-management is defined as the management of the symptoms, treatment, physical and psychosocial consequences and lifestyle changes inherent in living with a chronic condition (Barlow et al., 2002). Efficacious self-management encompasses the ability to monitor one's condition and to effect the cognitive, behavioural and emotional responses necessary to maintain a satisfactory quality of life (Barlow et al., 2002). However, people need support from health care professionals and significant others to be able to self-manage (Dwarswaard et al., 2015). Particularly at a later age, the ability to carry out activities of daily living and to adapt and to manage one's own life decreases due to the deterioration of one's physical and cognitive condition. In line with this, health care professionals should support the self-management ability of older adults with interventions aimed at empowering elderly people (CSO et al., 2012). Self-management support interventions are defined as all educational and supportive interventions, systematically provided by health care staff, to increase patients' skills and confidence in managing their health problems, including regular assessment of progress and problems, goal setting and problem-solving support (Adams et al., 2004). By supporting the self-management ability of older adults, nurses and other health care professionals can contribute to the prevention of activities of daily living dependence and increase the ability to adapt and to selfmanage the consequences of living with a chronic condition. Pursuant to the above considerations, the main objective of this systematic review was to identify, appraise and synthesize the evidence of the effects of self-management support programmes on the activities of daily living abilities of older adults.

The main review question was:

- What evidence can be derived from existent studies about the effects of self-management support programmes on the activities of daily living abilities of older adults?

- $\quad$ In order to interpret and value the effects properly, two additional questions were formulated, namely:

- What are the characteristics of effective self-management support programmes in the relevant studies?

- What is the methodological quality of the relevant studies?

\section{METHOD}

The methodology used for this systematic review was based on the guidance for conducting systematic reviews, the Cochrane Handbook for Systematic Reviews of Interventions (Higgins and Green, 2011). 
Bolscher-Niehuis, M.J.T van het, Ouden, M.E.M. den, Vocht, H.M. de, Francke, A.L. Effects of self-management support programmes on activities of daily living of older adults: a systematic review. International Journal of Nursing Studies: 2016, 61(9), 230-247

\subsection{Inclusion and exclusion criteria}

Self-management support programmes can be used for many purposes but this systematic review only focussed on the effects of self-management support programmes on (or directly related to) activities of daily living of older adults as defined by Katz et al. (1963) and Lawton and Brody (1969). The self-management support programme should be an educational and supportive intervention, systematically provided by health care staff, to increase patients' skills and confidence in managing their health problems (Adams et al., 2004) and the effects should be measured within a randomized controlled trial.

The following inclusion criteria were used for the selection of studies for this review:

1. The study concerns adults, mean age 65 years or older, and living in the community.

2. The study focuses on self-management support programmes as defined by Adams et al. (2004).

3 . The study is a randomized controlled trial.

4. The study presents outcomes of self-management support programmes on basic or instrumental activities of daily living.

The following exclusion criteria were applied:

1.The study concerns older adults whose main diagnosis is dementia or psychiatric illness.

2.The study presents outcomes of self-management support interventions that are not directly related or linked to basic or instrumental activities of daily living (e.g. clinical outcomes, patient satisfaction, health care utilization or costs).

3.The study is only published as an abstract, editorial comment, commentary, letter or a study protocol.

No language, country or period restrictions were imposed.

\subsection{Searches in databases}

A systematic search of the literature was conducted in February 2016. Computerbased literature searches were performed in PubMed, EMBASE, CINAHL, PsycINFO and the Cochrane Central Register of Controlled Trials. The search strategy used for PubMed is shown in Box 1.

\section{[BOX 1]}

Comparable search strategies were used for the other literature databases. These search strategies are available on request.

After combining the results of the different databases, 6246 references were found. After removal of duplicates, 5220 potentially relevant references remained.

\subsection{Selection}

The Preferred Reporting Items for Systematic Reviews and Meta-Analysis flow diagram was used to summarize the study selection processes (see Fig. 1). In the initial selection phase, two authors $(\mathrm{MvhB}$ and $\mathrm{MdO})$ independently screened titles 
Bolscher-Niehuis, M.J.T van het, Ouden, M.E.M. den, Vocht, H.M. de, Francke, A.L. Effects of self-management support programmes on activities of daily living of older adults: a systematic review. International Journal of Nursing Studies: 2016, 61(9), 230-247

and abstracts to identify potentially relevant studies. It was stipulated beforehand that if there was substantial agreement between the two reviewers in a sample of $10 \%$ of all non-duplicate references, the remaining $90 \%$ of the sample would be screened only by the first author. In the sample, the interrater agreement was very high (Kappa value 0.83) (Landis and Koch, 1977). Any reference for which the decision on inclusion or exclusion was unclear was discussed with the second reviewer. References were included in the next selection phase when at least one of the two reviewers included the study based on the inclusion criteria. A total of 169 references were found eligible for further screening.

\section{[FIGURE 1]}

In the next selection phase, the full texts of these references $(n=169)$ were examined independently by two researchers (MvhB and MdO or HdV or AF). The reviewers' selections of studies were compared and differences or doubts were discussed until both authors agreed on inclusion or exclusion. In this selection phase, 157 publications were excluded. The main reasons for exclusion were:

- $\quad$ the self-management support intervention did not concern older adults with a mean age of 65 years of older;

- $\quad$ the study focussed only on outcomes not related to the activities of daily living of older adults.

A final set of 12 publications met the inclusion criteria.

\subsubsection{Assessment of methodological quality}

The assessment of the methodological quality of the included studies was performed independently by two reviewers (MvhB and MdO or HdV or AF) using the quality criteria for reviews of the Cochrane Effective Practice and Organisation of Care Review Group (Effective Practice and Organisation of Care, 2015). Disagreements in methodological quality scores were resolved by discussion. The following nine standard criteria were used for the assessment of the risk of bias for studies with a separate control group: adequate sequence generation, concealment of allocation, baseline outcome similarity, baseline characteristics similarity, adequately addressed incomplete outcome data, blinding, protection against contamination, selective outcome reporting and other risk of bias.

The Cochrane guidelines (Higgins and Green, 2011) were used to summarize the risk of bias for the outcome (i.e., activities of daily living). The domains 'allocation', 'incomplete outcome data' and 'selective reporting' were identified as the key domains in this summary assessment. The risk of bias for the outcome was judged as 'low risk of bias' if the study showed a low risk of bias for all key domains, 'unclear risk of bias' if there was an unclear risk of bias for one or more key domains and 'high risk of bias' if there was a high risk of bias for one or more key domains.

\subsection{Data extraction and synthesis}

The first author (MvhB) extracted information from each included study. The data extraction was checked by the other authors ( $\mathrm{MdO}, \mathrm{HdV}, \mathrm{AF})$. This phase resulted in an overview of the methods, results and conclusions of the studies (see Table 1) and 
Bolscher-Niehuis, M.J.T van het, Ouden, M.E.M. den, Vocht, H.M. de, Francke, A.L. Effects of self-management support programmes on activities of daily living of older adults: a systematic review. International Journal of Nursing Studies: 2016, 61(9), 230-247

a description of the characteristics of the self-management support programmes of the included studies (see Table 2).

\section{[TABLE 1]}

No statistical pooling of outcomes was performed, because there was considerable heterogeneity regarding the clinical characteristics of the participants, the interventions included and the outcomes measured. In addition, due to the low methodological quality of the studies a meta-analyses is less appropriate (Higgins and Green, 2011). A best evidence synthesis was performed (van Tulder et al., 2003) by attributing various levels of evidence to the effectiveness of a self-management support programme, taking into account the characteristics of the participants and the intervention, the outcomes and the methodological quality of the original studies.

Level 1: Strong evidence - provided by generally consistent findings in multiple high-quality randomized controlled trials.

Level 2: Moderate evidence - provided by generally consistent findings in one highquality randomized controlled trial and/or more relevant low-quality randomized controlled trials and/or controlled clinical trials.

Level 3: Limited evidence - provided by generally consistent findings in one or more low-quality randomized controlled trials and/or controlled clinical trials.

Level 4: No or conflicting evidence - if there were no randomized controlled trials or if the results were conflicting (van Tulder et al., 2003).

\section{RESULTS}

To appraise and synthesize the evidence of the effects of self-management support programmes on the activities of daily living of older adults, the characteristics and the methodological quality of the included studies and the characteristics of the selfmanagement support programmes are described in Table 1 and Table 2, respectively.

\subsection{Methods of the included studies}

\subsubsection{Designs}

All studies $(n=12)$ used a randomized controlled design. Outcomes of older adults participating in a self-management support programme were compared with outcomes of the control group who did not receive the key elements of the selfmanagement support programme. The control group received care as usual $(n=6)$ and/or an educational leaflet/booklet $(n=3)$ or a tour at the senior centre $(n=1)$. In the study by Sundsli et al. (2014) the control group did not receive any intervention or attention at all and in the study by Alp et al. (2007) the control subjects were instructed to maintain their sedentary lifestyle. The control group in the study by Coleman et al. (2012) received the intervention afterwards.

In all studies, measurements were performed at baseline and after the intervention period (range from five weeks to a two-year period). Sometimes, mainly in studies with a short intervention period, measurements were also performed after a prolonged period, of three to six months. 
Bolscher-Niehuis, M.J.T van het, Ouden, M.E.M. den, Vocht, H.M. de, Francke, A.L. Effects of self-management support programmes on activities of daily living of older adults: a systematic review. International Journal of Nursing Studies: 2016, 61(9), 230-247

\subsubsection{Study population}

The sample size of the included studies varied from 30 to 766 participants. The studies were heterogeneous with respect to the mean age of the participants (range 65-83 years) and the types of diseases or disabilities of the sample (e.g. osteoarthritis, osteoporosis, heart disease, age related vision loss). Although almost all studies included male and female participants, there was a minority of male participants in most of the study populations.

\subsubsection{Outcome variables, instruments and data analysis}

The outcome variables of the studies varied and there was also a considerable variation in the measurement instruments used. Most studies used validated (selfrating) questionnaires or scales (e.g. the Short Form (36), the Health Assessment Questionnaire, the Self-Care Ability Scale for the Elderly) in combination with (semi-) structured interviews. A minority of the studies (also) used physical tests. Because the main focus of this systematic literature review is on the effects of selfmanagement support programmes on the activities of daily living of older adults, only the findings on those outcomes (e.g. physical functioning, physical role functioning and (instrumental) activities of daily living-dependence) are presented (see Table 1).

\subsubsection{Methodological quality assessment}

The results of the methodological assessment are presented in Table 1 and Fig. 2.

\section{[FIGURE 2]}

The key domains in the summary assessment of the risk of bias for the outcome on the activities of daily living were 'allocation', 'incomplete outcome data' and 'selective reporting'.

As for allocation, in the majority of the included studies $(n=7)$ the method used to conceal the allocation sequence remained 'unclear' ( Alp et al., 2007, Elzen et al., 2007, Ersek et al., 2003, Friedman et al., 2009, Friedman et al., 2014, Meng et al., 2007 and Sundsli et al., 2014). In one study, this criterion was appraised as 'high risk of bias' because the control group had access to activities that were available to the intervention group (Leveille et al., 1998).

Another key criterion of the methodological assessment was whether incomplete outcome data were likely to bias the results. In most of the studies, this domain was judged as 'high risk' $(n=6)$ or 'unclear risk' $(n=3)$ due to a high rate of (selective or voluntary) drop-outs or lost-to-follow-up (i.e., in the study of Friedman et al., 2009, Meng et al., 2009 and Wetzels et al., 2008).

For the third key criterion, selective outcome reporting, the risk of bias was judged as 'low' in 9 of the 12 included studies (i.e., in the study of Alp et al., 2007, Coleman et al., 2012, Elzen et al., 2007, Ersek et al., 2003 and Girdler et al., 2010). If not all relevant outcomes in the methods section were reported in the results section (i.e., in the study by Meng et al., 2009) this domain was assessed as 'high risk'. Concerning the criterion of blinding: blinding of participants and clinical/research team members to group allocation whilst participating in or delivering the intervention is difficult and a lot of studies used self-rated questionnaires or interviews for assessing the outcomes. Only when blinding to group allocation was 
Bolscher-Niehuis, M.J.T van het, Ouden, M.E.M. den, Vocht, H.M. de, Francke, A.L. Effects of self-management support programmes on activities of daily living of older adults: a systematic review. International Journal of Nursing Studies: 2016, 61(9), 230-247

described explicitly or it was clearly stated that the assessor was not involved in the intervention, the risk of bias for this domain was 'low'.

There were important concerns about other risks of bias, not addressed in the domains of the used risk of bias tool; for example, a small sample size (Sundsli et al., 2014) or using measurement instruments that had not been validated (Ersek et al., 2003). Only in the studies by Alp et al. (2007), Leveille et al. (1998) and Wetzels et al. (2008) was there no evidence of other risks of bias.

\subsection{Characteristics of the programmes}

\subsubsection{Intensity and duration}

Three types of self-management support programmes were identified. First, there were intensive programmes with a short duration ( $<$ six months) and weekly group sessions (Alp et al., 2007, Coleman et al., 2012, Elzen et al., 2007 and Ersek et al., 2003). Second, there were less intensive programmes ( $\leq$ one session a month), with a long duration ( $\geq$ one year), using an individual approach (Friedman et al., 2009, Friedman et al., 2014, Leveille et al., 1998, Meng et al., 2007 and Meng et al., 2009). Third, there were three programmes with an intermediate duration of 6-12 months, a less intensive programme ( $\leq$ one session a month) and individual and/or group sessions (Girdler et al., 2010, Sundsli et al., 2014 and Wetzels et al., 2008).

\subsubsection{Topics and key elements of the self-management support programmes}

All studies used a self-management support programme with a multi-component structure. Core elements of the self-management support programmes were: health promotion and information about the disease, education aimed at knowledge, skills and strategies to manage the consequences of the disease/disability, coaching of health behaviour changes using a personal plan or individual goals, social support through communication with peers or professionals and functional training/exercises. In the main a combination of disease-specific information, education of knowledge and skills and coaching of health behaviour changes or problem solving was used.

\subsection{Effects on the activities of daily living}

Most of the included studies presented a large number of findings, but this review only focussed on the effects of self-management support programmes on the activities of daily living of older adults.

It turns out that the results of the studies (regardless their methodological quality and heterogeneity) nearly all point in the same direction. All studies (both with a low and high risk of bias), except for the study by Elzen et al. (2007), showed that the selfmanagement support programme led to less disability in the activities of daily living of older adults. However, the specific outcome variables varied, and some studies found improvements in the activities of daily living even though no statistical significance could be established. Examples of studies showing significant effects were the research of Alp et al. (2007) and Coleman et al. (2012), which showed that a programme with a short duration and weekly group sessions aimed at health promotion and health behaviour changes led to significant improvements in physical functioning and physical role functioning, as measured by the Short Form (36) subscales. These improvements were still present at six months. Alp et al. (2007) even demonstrated a significant decrease in physical role functioning in the control group. 
Bolscher-Niehuis, M.J.T van het, Ouden, M.E.M. den, Vocht, H.M. de, Francke, A.L. Effects of self-management support programmes on activities of daily living of older adults: a systematic review. International Journal of Nursing Studies: 2016, 61(9), 230-247

In addition, in the study by Ersek et al. (2003), participants of the seven-week selfmanagement group intervention differed significantly in pre-treatment to posttreatment changes in physical role function scores compared to the control group. However, the intervention group did not seem to have had a significant impact at the post-treatment evaluation of physical functioning, and at the three-month evaluation there were no significant differences between the groups in any outcome. Studies concerning multicomponent self-management support interventions with a less intensive programme of an individual nature and with a long duration demonstrated the same findings. For example, Friedman et al. (2009) and Meng et al. (2007) showed that the intervention group was dependent in fewer activities of daily living and had a significant reduction in the number of activities of daily living disabilities. However, both did not find a significant effect on instrumental activities of daily living. Also, in the studies by Leveille et al. (1998) the intervention led to higher levels of physical activity. Meng et al. (2009) concluded that the decline in function was much smaller in the intervention group.

In addition to these results, Girdler et al. (2010) found that the experimental group (usual care and a structured programme delivered in a group environment) showed significantly better physical health and participation levels, while those receiving just the usual care experienced decline, also at the 12-week follow-up.

In the studies by Sundsli et al. (2014) and Wetzels et al. (2008), both concerning a less intensive programme ( $\leq$ one session a month) of an individual nature and with a duration of six months, no significant differences were found in the before-after measurement scores on the Self-Care Ability Scale for the Elderly and the Appraisal of Self-Care Agency Scale, respectively the Arthritis Impact Measurement Scales physical functioning and social functioning. It is, however, remarkable that these studies showed worse outcomes in the control group. In particular, intervention programmes using a personalized plan, tailored to the participants' individual goals or targeting individually identified problems, led to (statistically significant) better outcomes (Girdler et al., 2010, Leveille et al., 1998 and Meng et al., 2007) compared to the programme not including this component (Elzen et al., 2007).

\section{DISCUSSION}

This review showed that self-management support programmes can contribute to the activities of daily living of older adults living in the community. In seven of the 12 included studies (both with a low and high risk of bias), the self-management support programme led to a statistically significant difference in the activities of daily living between the results of the intervention group and those of the control group (Alp et al., 2007, Coleman et al., 2012, Ersek et al., 2003, Friedman et al., 2009, Girdler et al., 2010, Leveille et al., 1998 and Meng et al., 2007). These differences were maintained at follow-up in three of the six studies that measured the effect of the programme post-treatment and at the three to six-month follow-up (Alp et al., 2007, Coleman et al., 2012 and Girdler et al., 2010). Although a statistically significant improvement in the physical functioning of the intervention group was not always demonstrated, in some studies, the control group showed a functional decline in activities of daily living ability. Perhaps the self-management support intervention may not always lead to a significant improvement in physical functioning, but it may prevent or delay the decline of activities of daily living in older adults. 
Bolscher-Niehuis, M.J.T van het, Ouden, M.E.M. den, Vocht, H.M. de, Francke, A.L. Effects of self-management support programmes on activities of daily living of older adults: a systematic review. International Journal of Nursing Studies: 2016, 61(9), 230-247

Self-management support interventions with a multi-component structure, consisting of disease-specific information, education of knowledge and skills and, in particular, coaching on health behaviour changes and problem solving through a personalized plan, resulted in improvements in physical functioning and the activities of daily living.

The intensity and duration of the programme does not seem to affect the results. All types of self-management support programmes, i.e., not only programmes with a short duration and weekly group sessions, but also less intensive programmes of an individual nature and with a long(er) duration, demonstrated improvements in the activities of daily living of older adults.

This review focused on the effects of self-management support programmes on the activities of daily living. Self-management support programmes are not only used to improve the physical functioning and activities of daily living but also have proven to be useful and beneficial with respect to health related quality of life (Ahmadi et al., 2015, Franek, 2013 and Zwerink et al., 2014), self-efficacy (Franek, 2013 and Jonker et al., 2009) disease specific self-care behaviour (Franek, 2013 and Jonker et al., 2009) and cost effectiveness (Ravesloot et al., 2016 and Zwerink et al., 2014).

Most of the included studies showed improvements in the physical functioning and activities of daily living of older adults. For older adults who participated in a selfmanagement support programme, the effects on activities of daily living seemed beneficial, but the effect of the intervention cannot be determined for people who dropped out or were lost to follow up. It is worth mentioning that, as a result of the low methodological quality of the included studies, the results may be biased due to a high rate of drop-outs or lost-to-follow-up. On the other hand, studies with low dropout rates (Girdler et al., 2010, Ersek et al., 2003 and Leveille et al., 1998) showed significant results.

In addition, there might be publication bias, due to the policy of and statistical reasons for scientific journals to prefer studies with positive results. This may therefore result in an overestimation of the effect of self-management support programmes. However, studies were included in the present review that reported no significant effect of self-management support programmes on the activities of daily living of older adults (Elzen et al., 2007, Friedman et al., 2014, Meng et al., 2009, Sundsli et al., 2014 and Wetzels et al., 2008).

In some studies a small sample size was used (Alp et al., 2007, Ersek et al., 2003, Girdler et al., 2010 and Sundsli et al., 2014). The results of these studies may be biased due to a small sample size. On the other hand, the results were consistent with the results of studies that used a large sample size (Friedman et al., 2009, Friedman et al., 2014 and Meng et al., 2009).

It is important to highlight that the self-management support programmes in a lot of studies were provided in addition to usual care. It is possible that the effectiveness of the programmes lies in the interaction between these two types of service provided. Perhaps a complementary approach should be applied when developing or implementing self-management support interventions for older adults living in the community.

In the included studies there was considerable variation in the measurement instruments used. This has resulted in a diversity of activities of daily living and instrumental activities of daily living outcome measures. Due to the scarcity of 
commonly used valid measurement instruments for activities of daily living and instrumental activities of daily living it was difficult to compare the results of the included studies. In addition, whilst in most studies activities of daily living were included as a primary outcome, they were included as both primary and secondary outcomes in Girdler et al's (2010) study. This may limit the conclusion about the effectiveness of the interventions as the power is based on the primary outcomes. Due to the heterogeneity of the included studies (varying by design, measurement instruments, target group and characteristics of the intervention) and the methodological quality of the studies, it is difficult to make general statements about the level of evidence. Based on consistent findings among multiple low quality randomized controlled trials and one high quality randomized controlled trial, a moderate level of evidence for the positive effects of self-management support interventions on the activities of daily living of older adults could be designated.

\section{CONCLUSION}

There is a moderate level of evidence that self-management support programmes with a multi-component structure, containing disease-specific information, education of knowledge and skills and, in particular, individually tailored coaching, improve the activities of daily living of older adults.

The findings provided by this review might be useful for nurses and other health care professionals who intend to design tailored self-management support interventions for older adults to remain independent in their activities of daily living. Further research is required to provide evidence to determine the most appropriate context (individually or in groups) and approach (in addition to usual care or not) of selfmanagement support interventions targeting the basic and instrumental activities of daily living of older adults living in the community. It is recommended to use randomized controlled trials with standardized outcome measurement instruments to measure the effects of the intervention on activities of daily living.

\section{Contributions}

The authors would like to thank Dr. Ad Bergsma of the Centre for Nursing Research at Saxion University of Applied Sciences for his writing assistance and proofreading the manuscript.

\section{Conflict of interest}

All authors disclose no conflict of interest.

\section{Funding}

No external funding was received.

\section{Ethical approval}

The authors declare that no ethical approval was required for this systematic literature study.

\section{REFERENCES}

Adams, K., Greiner, A.C., Corrigan, J.M. (Eds.), 2004. Report of a Summit. The 1st Annual Crossing the Quality Chasm Summit: A Focus on Communities. National Academies Press, Washington, DC. 
Bolscher-Niehuis, M.J.T van het, Ouden, M.E.M. den, Vocht, H.M. de, Francke, A.L. Effects of self-management support programmes on activities of daily living of older adults: a systematic review. International Journal of Nursing Studies: 2016, 61(9), 230-247

Ahmadi, M., Jahani, S., Poormansouri, S., Shariati, A., Tabesh, H., 2015. The effectiveness of self management program on quality of life in patients with sickle cell disease. Iran. J. Pediatr. Hematol. Oncol. 5, 18-26.

Alp, A., Kanat, E., Yurtkuran, M., 2007. Efficacy of a self-management program for osteoporotic subjects. Am. J. Phys. Med. Rehabil. 86 (8), 633-640, http://dx.doi.org/10.1097/PHM.0b013e31806dd428.

Barlow, J., Wright, C., Sheasby, J., Turner, A., Hainsworth, J., 2002. Self- management approaches for people with chronic conditions: a re- view. Patient Educ. Couns. 48 (2), 177-187.

Coleman, S., Briffa, N.K., Carroll, G., Inderjeeth, C., Cook, N., McQuade, J., 2012. A randomised controlled trial of a self-management education program for osteoarthritis of the knee delivered by health care professionals. Arthritis Res. Ther. 14 (1), R21, http://dx.doi.org/10.1186/ar3703.

CSO, NFU, ZonMw, 2012. The Future of Geriatric Care; Core Values, Outcomes and Perspective, The Vision of CSO, NFU and ZonMw.

Dwarswaard, J., Bakker, E.J., van Staa, A., Boeije, H.R., 2015. Self-manage- ment support from the perspective of patients with a chronic condi- tion: a thematic synthesis of qualitative studies. Health Expect., http://dx.doi.org/10.1111/hex.12346.

Elzen, H., Slaets, J.P., Snijders, T.A., Steverink, N., 2007. Evaluation of the chronic disease self-management program (CDSMP) among chroni- cally ill older people in the Netherlands. Soc. Sci. Med. 64 (9), 1832-1841, http://dx.doi.org/10.1016/j.socscimed.2007.02.008.

Effective Practice and Organisation of Care (EPOC), 2015. Suggested Risk of Bias Criteria for EPOC Reviews. EPOC-Specific Resources for Review Authors. Norwegian Knowledge Centre for the Health Services, Oslo. Available at http://epoc.cochrane.org/epoc-specificresources- review-authors.

Ersek, M., Turner, J.A., McCurry, S.M., Gibbons, L., Kraybill, B.M., 2003. Efficacy of a self-management group intervention for elderly persons with chronic pain. Clin. J. Pain 19 (3), 156-167.

Franek, J., 2013. Self-management support interventions for persons with chronic disease: an evidence-based analysis. Ont. Health Technol. Assess. Ser. 13 (9), 1-60.

Fried, L.P., Tangen, C.M., Walston, J., Newman, A.B., Hirsch, C., Gottdiener, J., Seeman, T., Tracy, R., Kop, W.J., Burke, G., McBurnie, M.A., Group CHSCR, 2001. Frailty in older adults: evidence for a phenotype. J. Gerontol. A: Biol. Sci. Med. Sci. 56 (3), M146-M156.

Friedman, B., Li, Y., Liebel, D.V., Powers, B.A., 2014. Effects of a home visiting nurse intervention versus care as usual on individual activities of daily living: a secondary analysis of a randomized controlled trial. BMC Geriatr. 14, 24, http://dx.doi.org/10.1186/ 1471-2318-14-24.

Friedman, B., Wamsley, B.R., Liebel, D.V., Saad, Z.B., Eggert, G.M., 2009. Patient satisfaction, empowerment, and health and disability status effects of a disease management-health promotion nurse interven- tion among Medicare beneficiaries with disabilities. Gerontologist 49 (6), 778-792, http://dx.doi.org/10.1093/geront/gnp090.

Girdler, S.J., Boldy, D.P., Dhaliwal, S.S., Crowley, M., Packer, T.L., 2010. Vision selfmanagement for older adults: a randomised controlled trial. Br. J. Ophthalmol. 94 (2), 223228, http://dx.doi.org/10.1136/ bjo.2008.147538.

Higgins, J.P.T., Green, S., 2011. Cochrane Handbook for Systematic Reviews of Interventions Version 5.1.0 [updated March 2011]. The Cochrane Collaboration. Available at www.cochrane-handbook.org.

Jonker, A., Comijs, H.C., Knipscheer, K., Deeg, D.J.H., 2009. Promotion of self-management in vulnerable older people: a narrative literature review of outcomes of the Chronic Disease Self-Management Program (CDSMP). Eur. J. Ageing 6, 303-314.

Katz, S., Ford, A.B., Moskowitz, R.W., Jackson, B.A., Jaffe, M.W., 1963. Studies of illness in the aged. The index of ADL: a standardized measure of biological and psychosocial function. JAMA 185, 914-919.

Landis, J.R., Koch, G.G., 1977. The measurement of observer agreement for categorical data. Biometrics 33 (1), 159-174.

Lawton, M.P., Brody, E.M., 1969. Assessment of older people: self-main- taining and instrumental activities of daily living. Gerontologist 9 (3), 179-186. 
Bolscher-Niehuis, M.J.T van het, Ouden, M.E.M. den, Vocht, H.M. de, Francke, A.L. Effects of self-management support programmes on activities of daily living of older adults: a systematic review. International Journal of Nursing Studies: 2016, 61(9), 230-247

Leveille, S.G., Wagner, E.H., Davis, C., Grothaus, L., Wallace, J., LoGerfo, M., Kent, D., 1998. Preventing disability and managing chronic illness in frail older adults: a randomized trial of a community-based partner- ship with primary care. J. Am. Geriatr. Soc. 46 (10), $1191-1198$.

Meng, H., Wamsley, B., Liebel, D., Dixon, D., Eggert, G., Van Nostrand, J., 2009. Urbanrural differences in the effect of a Medicare health promotion and disease selfmanagement program on physical func- tion and health care expenditures. Gerontologist 49 (3), 407-417, http://dx.doi.org/10.1093/geront/gnp057.

Meng, H., Wamsley, B.R., Eggert, G.M., Van Nostrand, J.F., 2007. Impact of a health promotion nurse intervention on disability and health care costs among elderly adults with heart conditions. J. Rural Health 23 (4), 322-331, http://dx.doi.org/10.1111/j.17480361.2007.00110.x.

Pulvirenti, M., McMillan, J., Lawn, S., 2014. Empowerment, patient centred care and selfmanagement. Health Expect. 17, 303-310.

Ravesloot, C., Seekins, T., Traci, M., Boehm, T., White, G., Witten, M.H., Monson, J., 2016. Living well with a disability, a self-management program. MMWR Suppl. 65 (1), 61-67, http://dx.doi.org/10.15585/ mmwr.su6501a10.

Rochat, S., Cumming, R.G., Blyth, F., Creasey, H., Handelsman, D., Le Couteur, D.G., Naganathan, V., Sambrook, P.N., Seibel, M.J., Waite, L., 2010. Frailty and use of health and community services by com-munity-dwelling older men: the Concord Health and Ageing in Men Project. Age Ageing 39 (2), 228-233, http://dx.doi.org/10.1093/ageing/afp257.

Sundsli, K., Soderhamn, U., Espnes, G.A., Soderhamn, O., 2014. Self-care telephone talks as a health-promotion intervention in urban home-living persons $75+$ years of age: a randomized controlled study. Clin. Interv. Aging 9, 95-103, http://dx.doi.org/10.2147/cia.s55925.

van Tulder, M., Furlan, A., Bombardier, C., Bouter, L., 2003. Updated method guidelines for systematic reviews in the cochrane collabora-tion back review group. Spine (Phila Pa 1976) 28 (12), 1290-1299, http://dx.doi.org/10.1097/01.brs.0000065484.95996.af.

Vermeulen, J., Neyens, J.C., van Rossum, E., Spreeuwenberg, M.D., de Witte, L.P., 2011. Predicting ADL disability in community-dwelling elderly people using physical frailty indicators: a systematic re- view. BMC Geriatr. 11, 33, http://dx.doi.org/10.1186/1471-231811-33.

Wetzels, R., van Weel, C., Grol, R., Wensing, M., 2008. Family practice nurses supporting self-management in older patients with mild osteoarthritis: a randomized trial. BMC Fam. Pract. 9, 7, http:// dx.doi.org/10.1186/1471-2296-9-7.

Zwerink, M., Brusse-Keizer, M., van der Valk, P.D., Zielhuis, G.A., Mon-ninkhof, E.M., van der Palen, J., Frith, P.A., Effing, T., 2014. Self management for patients with chronic obstructive pulmonary dis-ease. Cochrane Database Syst. Rev. 3, CD002990, http://dx.doi.org/ 10.1002/14651858.CD002990.pub3. 
Bolscher-Niehuis, M.J.T van het, Ouden, M.E.M. den, Vocht, H.M. de, Francke, A.L. Effects of self-management support programmes on activities of daily living of older adults: a systematic review. International Journal of Nursing Studies: 2016, 61(9), 230-247

\section{BOX AND TABLES}

\section{Box 1.}

Search strategy in Pubmed.

(((“Aged”[Mesh] OR “aged”[tiab] OR “older adults”[tiab] OR “older patients”[tiab] OR “older people"[tiab] OR "ageing population"[tiab] OR "ageing population"[tiab] OR "elderly"[tiab] OR "elder patients"[tiab] OR "elder people”[tiab]) AND ((“Selfmanagement"[tiab] OR "self care"[Mesh] OR "self-care"[tiab]) AND

(“support”[tiab] OR “intervention"[tiab] OR “intervention studies”[Mesh] OR "method"[tiab] OR strateg*[tiab] OR "system"[tiab] OR "program"[tiab] OR "programme"[tiab])) AND ("Activities of Daily Living"[Mesh] OR "Self Care"[Mesh] OR "self-care"[tiab] OR "self care"[tiab] OR "ADL"[tiab] OR "activities of daily living"[tiab] OR "instrumental activities of daily living"[tiab] OR "IADL"[tiab]) AND ((clinical[Title/Abstract] AND trial[Title/Abstract]) OR clinical trials as topic[MeSH Terms] OR clinical trial[Publication Type] OR random*[Title/Abstract] OR random allocation[MeSH Terms] OR therapeutic use[MeSH Subheading])))

Fig. 1. Flow diagram of the searches and the selection process.

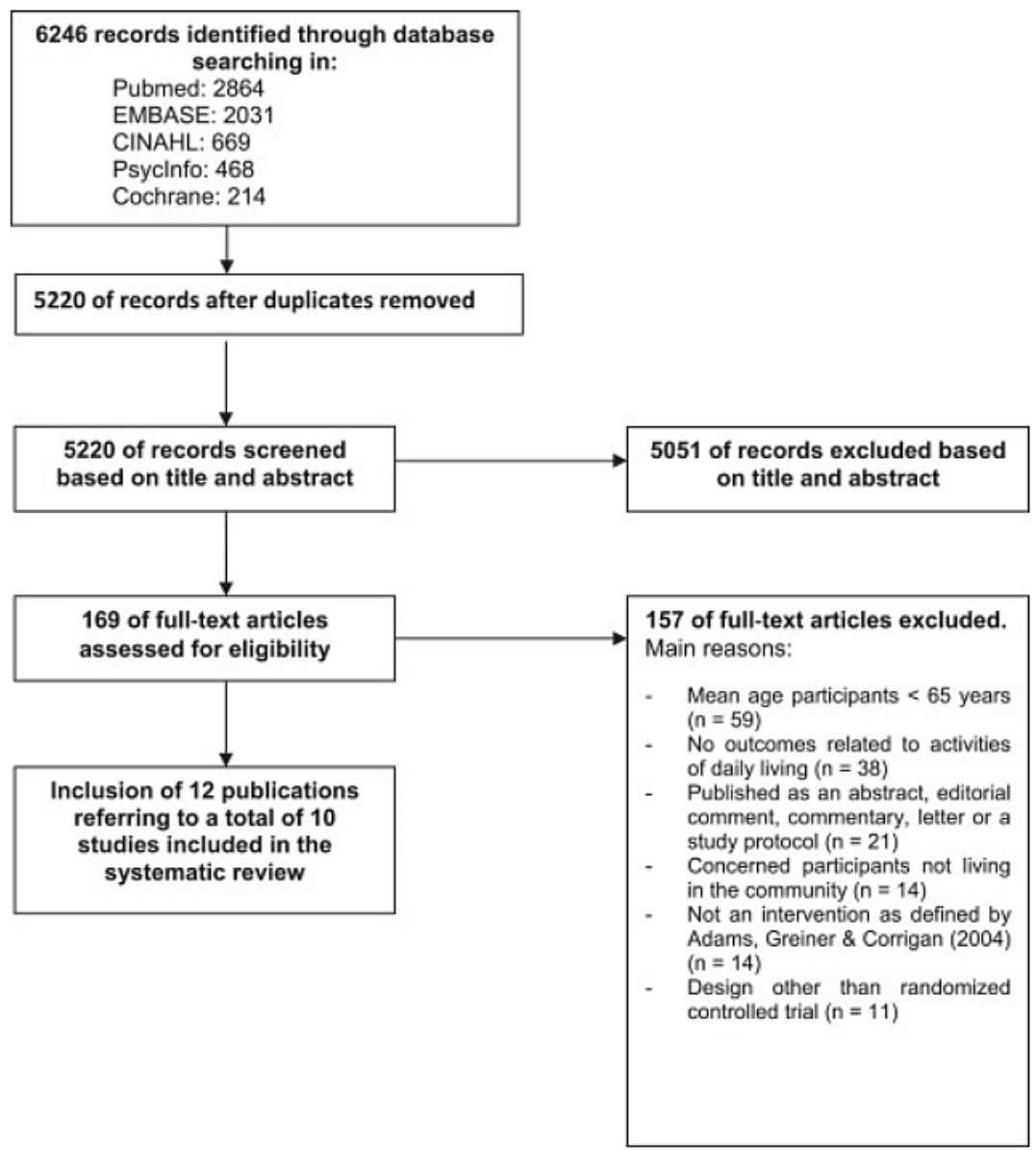


Table 1

Methodological study characteristics and effects measured.

\begin{tabular}{|c|c|c|c|c|}
\hline \multirow{2}{*}{$\begin{array}{l}\text { General } \\
\text { information } \\
\text { Author, year, } \\
\text { country, } \\
\text { language }\end{array}$} & \multirow{2}{*}{$\begin{array}{l}\text { Methodological } \\
\text { assessment } \\
\text { High/unclear/ } \\
\text { low risk of bias }\end{array}$} & \multicolumn{3}{|c|}{ Methodological characteristics } \\
\hline & & Design & Design features & Variables/instruments \\
\hline $\begin{array}{l}\text { Alp et al. (2007)/ } \\
\text { Turkey/English }\end{array}$ & Unclear risk & $\begin{array}{l}\text { Single-blind } \\
\text { randomized } \\
\text { controlled } \\
\text { longitudinal } \\
\text { study }\end{array}$ & $\begin{array}{l}\text { Self-management group } \\
(n=25) \text { and control group } \\
(n=25) \text {. Evaluations at } \\
\text { baseline, at the end of the } \\
\text { self-management class } \\
\text { (fifth week) and after six } \\
\text { months. }\end{array}$ & $\begin{array}{l}\text { Pain-intensity (VAS), Life-quality (SF36), } \\
\text { balance (SRT: Sensitized Romberg Test), } \\
\text { functional assessment by (TSS: Timed Sit } \\
\text { to Stand test) and a questionnaire to } \\
\text { measure positive and negative changes in } \\
\text { their lives. }\end{array}$ \\
\hline $\begin{array}{l}\text { Coleman } \\
\text { et al. (2012)/ } \\
\text { Australia/English }\end{array}$ & Unclear risk & $\begin{array}{l}\text { Randomized } \\
\text { controlled } \\
\text { trial }\end{array}$ & $\begin{array}{l}\text { Self-management group } \\
(n=75) \text { and control group } \\
(n=71) \text {. Assessments at } \\
\text { baseline, } 8 \text { weeks and } 6 \\
\text { months. }\end{array}$ & $\begin{array}{l}\text { Results Western Ontario and Mc Master } \\
\text { Universities Arthritis Index (WOMAC), } \\
\text { Pain and Function subscales on the Short } \\
\text { Form } 36 \text { version (SF-36), Pain (VAS), } \\
\text { Timed Up \& Go Test (TUG), knee range of } \\
\text { motion and quadriceps and hamstring } \\
\text { strength-isometric contraction. Responses } \\
\text { to treatment and minimal clinically } \\
\text { important improvements (MCIIs) were } \\
\text { determined. }\end{array}$ \\
\hline
\end{tabular}

Sample size and characteristics

Findings on ADL/IADL

50 sedentary $(<1.5 \mathrm{~km}$. of walking or $<4 \mathrm{~h}$ of standing per day)

women, postmenopausal and

idiopathic osteoporosis (DEXA T-

scores $<-2.5)$ (25 intervention

group/25 control group). Age: ( $M$

$(S D))=66(12))$ intervention

group: 64 (8), control group: 67

11). Gender = female $(100 \%)$.

SF-36PF ${ }^{1}$ intervention group (mean): Baseline: 59.1; 5th week: 78.6; 6th month: 83.8 and

control group (mean): Baseline: 64.3 ; 5th week:

63.4; 6th month: 63.4. SF-36 PRL intervention

group (mean): Baseline: 55.6 ; 5th week: 100; 6th

month: 100 and control group (mean): Baseline:

63.1; 5th week: 42.3 ; 6th month: 39.1

Significant improvements in SF-36PF $(p<0.001$,

$p<0.001)$ and SF-36PRL $(p<0.01, p<0.01)$ in

intervention group at the fifth week and sixth

month. In control group significant decreases in
SF-36PRL $(p<0.05$ at fifth week, $p<0.01$ at sixth SF-36PR
month).

146 primary care patients with osteoarthritis of the knee. Age: (mean (SD)): intervention group: 65 (7.9); control group: 65 (8.7) Gender (M:F): 37:109

Gender (M:F): $37: 109$
(intervention group: 14:57;

control group 23:52)

determined.

WOMAC Physical Function ${ }^{1}$ improved more

significantly in the OAK-group (Baseline: 241 ; weeks: 19.1; 6-months: 19.9) thaseline. 24.1; 8group (Baseline: $24.1 ; 8$-weeks: 24.4: 6-months: 23.4). The advantage in between-group differences in changes was evident in the

Physical Function at posttreatment $(-5.55$; 95\% CI -7.38; - 3.31) and 6-months follow-up $(-4.35 ; 95 \% \mathrm{Cl}-6.20 ;-0.91)$. There were improvements from baseline to 8 weeks in the SF-36 scales Physical Function ${ }^{1}$ (OAK: Baseline: 48.0, 8 -wels: $54.1 ; 6$ - months. 54.2 and control 4roup: Baselen: 48 : 6 - 8 -weserence in 48.5 theatment: 5.61; $95 \%$ CI 1,84; 9,37 and at 6 -months followup: 5.67; $95 \%$ CI $0.40 ; 10.93)$, and SF-36 Role Physical $^{1}$ (OAK: Baseline: 35.7; 8-weeks: 47.9; 6months: 46.0 and control group: Baseline: 35.7 ; 8-weeks: 30.8; 6-months: 38.6: difference in changes: 17.06 ; $95 \%$ CI 5.90; 28.21 but not at 6 months follow-up: $7.37,95 \% \mathrm{CI}-5.93 ; 20.67)$. These differences were maintained at 6 months (difference in changes SF-36 Physical Function: 5.67 and SF-36 Role Physical: 7.37).

Demographic data and data on selfefficacy (General Self-Efficacy Scale), selfmanagement behaviour (measured with adapted and translated versions of "Physical activities", "Coping with symptoms" and "Communication with physician" questionnaires) and health status (measured with the RAND-36-ite Health Survey; only the physical and mental component summary scales were used).
139 people (aged 59 or older) with a lung disease, a heart disease, diabetes, or arthritis. (interventio group $n=68$, control group $n=68))$ Age: (mean (SD)) intervention group 68.2 yrs. (6.0); control group: 68.5 (6.6) Gende (M:F): intervention group and 63.2\%); control group: idem.
RAND-36 Physical component ${ }^{1}$ : With regard to the physical component summary scale, no significant differences were found between the intervention and the control group at T1 or at T2. T2 [t(115) $=-0.137, p=0.45$, partial Z2 $1 / 4.00]$. course) and after 6 ,

course). 

6), depression (Geriatric Depression baseline, 9 weeks later (after treatment) and 3 thents after the post-
Patient characteristics (empowerment self-efficacy, self-rated health and disability status (SF-36 PCS and MCS) and (I) ADL-dependence (Shaughnessy)) obtained from a baseline interview (at patients homes, by trained interviewers, with patient (or a caregiver)) completed before each patient entered the study and 22 months after herr intervention start date. Information about satisfaction was collected in the nurse group at 10 and 20 months after start intervention.
45 Independent-living retirement cider) with pain (ms (60 yeas or clder) with pain (mothe he with regular activities. Age (me (SD)): intervention. (5.0): educational booktet group 80.3 yrs (6.6) Gender (M:F): . 91\%): education booklet group: 4:19 (17\%: $83 \%)$.

66 community living high-risk disability (need or receive help with $\geq 2$ ADL's or $\geq 3$ IADL's) an recent significant health care utilization who were expected to have high health care and Medicare expenditures during the next 2 years. Age: $(M(S D))=77,3$ (11.4). Intervention group: 77.2 (11.2); control group: 77.5 (11.7) Gender (M:F) 31.2\%: $68.8 \%$ Intervention group: $31.9 \%: 68.1 \%$ control group: $30.5 \%: 69.5 \%$
F-36 Role-physical ${ }^{1}$ : EB-group: Baseline: 20.7 Posttreatment; 21.7; 3 months follow-up: 28.4 41.7; 3 months follow-up: 28,4, SF-36 Physi Functioning ${ }^{1}$ : EB-group: Baseline: 40.9; posttreatment: $42.4 ; 3$ months follow-up: 43.0 postrent: 38.7; 3 months follow-up: 38.4 . The two differed significantly on pre-treatment to posttreatment conge in (Wilcoxon W: 436.5; $p=0.04$ ). The SMG participants showed greater improvement. The the post-treatment evaluation on physical functioning as measured by the SF-36 physical
functioning subscale. At 3-months, there were no significant differences between groups on any outcome.

At 22 months after baseline the nurse intervention had a significant effect (Baseline $=-0.25 ; \mathrm{SE}=0.12 ; p=.038)$ on $\mathrm{ADL}$ dependence (effect size $=.30$ ) (when the model included only the patients who had data reported by the same category of questionnaire respondent (patient or caregiver) at both timepoints). Compared with the control group, the patients in the nurse group were dependent in fewer ADLs. Six outliers were identified. When they were deleted, the nurse intervention had a slightly greater effect $(p=.030)$. No statistically significant nurse intervention effects were found for the other four health and disability status measures (Self-rated health status ${ }^{1}$, SF-36 PCS ( $\left(\right.$ Baseline $=0.14 ; \mathrm{SE}=0.77 ; p=0.86$ ) and $\mathrm{MCS}^{1}$, IADL-dependence ${ }^{1}$ (Baseline $=-0.16 ; \mathrm{SE}=0,12$ $p=0.18$ ). 


\begin{tabular}{|c|c|c|c|c|c|c|}
\hline \multirow{2}{*}{$\begin{array}{l}\text { General } \\
\text { information } \\
\text { Author, year, } \\
\text { country, } \\
\text { language }\end{array}$} & \multirow{2}{*}{$\begin{array}{l}\text { Methodological } \\
\text { assessment } \\
\text { High/unclear/ } \\
\text { low risk of bias }\end{array}$} & \multicolumn{4}{|c|}{ Methodological characteristics } & \multirow[t]{2}{*}{ Findings on ADL/IADL } \\
\hline & & Design & Design features & Variables/instruments & Sample size and characteristics & \\
\hline $\begin{array}{l}\text { Friedman } \\
\text { et al. (2014)/ } \\
\text { United States/ } \\
\text { English }\end{array}$ & High risk & $\begin{array}{l}\text { Randomized } \\
\text { controlled } \\
\text { trial }\end{array}$ & $\begin{array}{l}\text { Nurse intervention group } \\
(n=237) \text { and control } \\
\text { group }(n=262) \text {. Data } \\
\text { collection at baseline and } \\
\text { at } 22 \text { months postbaseline. }\end{array}$ & $\begin{array}{l}\text { Patient characteristics (health status, } \\
\text { lifestyle, health insurance, health-care } \\
\text { utilization) and ADL-dependence } \\
\text { obtained from a baseline interview (at } \\
\text { patients homes, by trained interviewers, } \\
\text { with patient (or a caregiver)) completed } \\
\text { before each patient entered the study and } \\
\text { at } 22 \text { months postbaseline. Data on } \\
\text { hospital and inpatient rehabilitation } \\
\text { expenditures were obtained from the } \\
\text { providers. }\end{array}$ & $\begin{array}{l}499 \text { community living Medicare } \\
\text { patients with disability (need or } \\
\text { receive help with } \geq 2 \text { ADL's or } \geq 3 \\
\text { IADL's) and recent significant } \\
\text { health care utilization. Age: }(M \\
(S D))=76.8 \text { (11.7). Gender: } 70 \% \\
\text { female. }\end{array}$ & 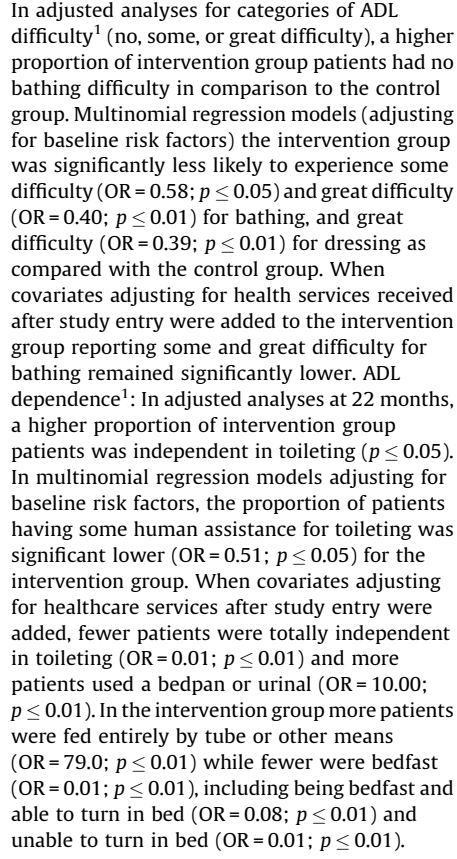 \\
\hline
\end{tabular}


Patient characteristics (socio-

characteristics) and participation levels (by Activity Card Sort (ACS)). Depressio (by Geriatric Depression Scale (GDS)) Quality of Life (SF-36), Generalized SelfEfficacy (by Generalised Self-Efficacy Scale (GSES), Adaptation (by Adaptation to self-efficacy (by Degerationefficacy Questionnaire). Data collection

(face to face structured interviews incl. administration of quest baseline immediately after the completion of rehabilitation and at 12 weeks follow-up.
7 independent community livin older adults with age-related

(6.7). Gender: 50 Female $(64.9 \%$;

27 Male (35.1\%).
Leveille

USA/English
High risk

\section{Randomized}

Nurse intervention group $(n=101)$ and control group $(n=100)$. Data collection at baseline an at 6 and 12 months after baseline.
Self-reported physical function, physical performance tests, health care utilization, and health behaviours by questionnaires and assessment visits at baseline and 6 and 12 months after baseline. Restricted activity days and bed disability days wer measured using items from the Nationa Health Interview Survey. Four SF-36 scales were used to measure role limitations caused by physical health and emotion problems, physical functioning, and general health. The Health Assessment Questionnaire (HAQ) was used to measure performance of activities of daily living. The Physical Activity Scale for the Elderly (PASE) was used to measure total leisure and work activity). The Physician-based Assessment and Counseling for Exercise (PACE) was used to assess attitudes and
behaviours related to physical activity. behaviours related to physical activity.
The Physical Performance and Mobility Exam (PPME) measures series of basic mobility tasks.
201 chronically ill older adults aged 70 and older. Age (Mea (SD): intervention group: 77.2 (5.2); control group: 76.9 (5.2) Gender: Intervention group:

female/male (63.4\%/36.6\%) contro

group: female/male (48.0\%/52.0\%).
Participants in the experimental group had statistilly betser paticiption level than the intervention partipipats demonstrated increase, then maintenance of participation in life situations (pretest (adj mean): 0.67 and postrest (mean) 0.72), while 'usual care' pand post. 0.67 and post-test (mean): 0.62). At post-test, those in the intervention group demonstrated $5 \%$ increase in participation, while those receiving 'usual care' alone experienced a $5 \%$ decline (effect size $=0.20$ ). . differences were sustained at 12 weeks follow-up (Mean $=0.72$ (intervention group) and 0.56 (usual care group): effect size $=0.31 ; p<0.001$ ). At post-test, the intervention participants also demonstrated significantly better physical health ${ }^{2}$ (SF-36 scores: pretest adj. mean: 36.07 and post-test: 38.16) when compared with the control group (SF-36 scores: pretest adj. mean: 36.07 and posttest: 33.29); (effect size: $0.10 ; p=0.005$ ). Scores remained largely unchanged from post-test to follow-up with intervention participants continuing to demonstrate better outcomes (mean intervention group: 38.86 and mean usual care group: 31.43 ); (effect size: $0.23 \cdot p=0.001$ ).

The intervention group had significantly fewer bed days ${ }^{1}$ than the control group during followup (intervention group: $100 \%(n=71)$ sustained high function and $0.0 \%(n=0)$ worsened; control group: $94.8 \%(n=73)$ sustained high function and $5.2 \%(n=4)$ worsened). Only the intervention group showed improvements in bed days during follow-up (intervention group: $29.2 \%(n=7)$ improved; control group: 0.0\% $(n=0)$ improved). Although modest differences were observe

between the study groups in changes in

restricted activity days', the differences were not statistically significant. The scores on the SF-36 scales $^{1}$ did not differ between the two groups. After adjustment for age, sex and baseline score the adjusted average HAQ-scores ${ }^{1}$ were $26 \%$ lower during follow-up in the intervention group ADL-difficulty $(0.23 \pm 0.02 ; 0.17 \pm 0.02$.

ADL-difficulty $(0.23 \pm 0.02 ; 0.17 \pm 0.02$,
respectively, $p=0.014)$. An investigation of health respectively, $p=0.014$ ). An investigation of health behaviour changes duning the study revealed that the intervention group inproved and behaviours with respect to physical activity. measured by the PACE score', compared with $(0.19)$ and control group (mean (SD)): $4.97(0.20)$, $p=0.028$ ). The overall level of physical activity measured by the PACE, was significantly higher in follow-up (intervention group (men (SD)): 1251 (4.1) and control group (mean (SD)): 112.1 (4.2), $p=0.031$ ). 


\begin{tabular}{|c|c|c|c|c|}
\hline \multirow{2}{*}{$\begin{array}{l}\text { General } \\
\text { information } \\
\text { Author, year, } \\
\text { country, } \\
\text { language }\end{array}$} & \multirow{2}{*}{$\begin{array}{l}\text { Methodological } \\
\text { assessment } \\
\text { High/unclear/ } \\
\text { low risk of bias }\end{array}$} & \multicolumn{3}{|c|}{ Methodological characteristics } \\
\hline & & Design & Design features & Variables/instruments \\
\hline $\begin{array}{l}\text { Meng } \\
\text { et al. (2007)/ } \\
\text { USA/English }\end{array}$ & High risk & $\begin{array}{l}\text { Randomized } \\
\text { controlled } \\
\text { trial }\end{array}$ & $\begin{array}{l}\text { Nurse intervention group } \\
(n=138) \text { and control } \\
\text { group }(n=143) \text {. Data } \\
\text { collection at baseline and } \\
\text { at } 22 \text { months after } \\
\text { baseline. }\end{array}$ & $\begin{array}{l}\text { Changes in functional status: measured by } \\
\text { the difference between the number of } \\
\text { Activities of Daily Living (ADL) } \\
\text { dependencies as reported by the patient or } \\
\text { his/her caregiver at baseline and at the 2- } \\
\text { year follow-up. (Data collection: } \\
\text { interviews by trained staff) Total health } \\
\text { care expenditures (cost by various payers } \\
\text { and intervention cost): data were } \\
\text { collected by using a utilization diary } \\
\text { completed by the participant or his/her } \\
\text { caregiver. (Utilization data were } \\
\text { converted to expenditures). }\end{array}$ \\
\hline $\begin{array}{l}\text { Meng } \\
\text { et al. (2009)/ } \\
\text { USA/ } \\
\text { English }\end{array}$ & High risk & $\begin{array}{l}\text { Randomized } \\
\text { controlled } \\
\text { trial }\end{array}$ & $\begin{array}{l}\text { Nurse intervention group } \\
(n=382 \text { (only } n=218 \text { in } \\
\text { analysis)) and control } \\
\text { group }(n=384 \text { (only } \\
n=234 \text { in analysis). Data } \\
\text { collection at baseline and } \\
\text { at } 22 \text { months after } \\
\text { baseline. }\end{array}$ & $\begin{array}{l}\text { Changes in functional status: measured by } \\
\text { the difference between the number of } \\
\text { Activities of Daily Living (ADL) } \\
\text { dependencies as reported by the patient or } \\
\text { his/her caregiver at baseline and at the 2- } \\
\text { year follow-up. (Data collection: } \\
\text { interviews by trained staff at participants' } \\
\text { homes) Data on health care service use } \\
\text { were collected via a weekly diary by the } \\
\text { participant or his/her caregiver. }\end{array}$ \\
\hline $\begin{array}{l}\text { Sundsli } \\
\text { et al. (2014)/ } \\
\text { Norway/ } \\
\text { English }\end{array}$ & High risk & $\begin{array}{l}\text { Randomized } \\
\text { controlled } \\
\text { study }\end{array}$ & $\begin{array}{l}\text { Intervention group }(n=15) \\
\text { and control group }(n=15) \text {. } \\
\text { Data collection before and } \\
\text { after the intervention. }\end{array}$ & $\begin{array}{l}\text { Self-reported perceived health, mental } \\
\text { health (The Coldberg's General Health } \\
\text { Questionnaire (GHQ-30), sense of } \\
\text { coherence (The Sense of Coherence (SOC- } \\
\text { 29) scale), self-care ability (The Self-Care } \\
\text { Ability Scale for the Elderly (SASE)), and } \\
\text { self-care agency (The Appraisal of Self- } \\
\text { Care Agency (ASA) scale). An open-ended } \\
\text { question about experiences of the } \\
\text { intervention was included in the last } \\
\text { questionnaire. Data were collected before } \\
\text { and after intervention (=after } 19 \text { weeks). }\end{array}$ \\
\hline
\end{tabular}

Findings on ADL/IADL

Sample size and characteristics

281 functionally impaired (at leas wo limitations in ADLs or at hree limitations in IADLs) community-living Medica conditions. Age (mean): $77 \mathrm{yrs}$ Gender: $67 \%$ Female.

766 elderly high-risk Medicare beneficiaries demonstratin impairment in physical functioning (at least two limitations in ADLs or at least three limitations in IADLs). Age (mean (SD)): intervention group: 75.9 (11.0) and control group: 75.7 (12.8). Gender: intervention
group: $71.1 \%$ female; control group: $71.4 \%$ female.

30 urban living individuals $75+$ years of age. Age Intervention roup: (mean (SD)): $8073(3.24)$ Control group: (mean (SD)): 80.73 (4.20). Gender: Female $(n=14)$ Male $(n=16)$.
The multivariate regression model adjusting for covariates showed that the nurse intervention resulted in improvement (i.e., reduction) in the number of ADL disabilities ${ }^{1}$ during 2-year followup (coefficient estimate $-.307, p=0.055$, see Table 2). The nurse intervention led to an improvement of 0.156 on the $0-6$ IADL scale ${ }^{1}$, but this effect was not significant $(p=0.321$, results not shown).

The average participant demonstrated functiona decline between the baseline and the 22-mon follow-up, as evident by the increased mean number of ADL dependencies ${ }^{1}$ over time. The decline in function was much smaller in the intervention group (changes in mean number of ADL: 1.97 at baseline and 2.21 after 22 months: differences $=0.23$ ) when compared with that of a control group (changes in mean number ADL: 1.98 at baseline and 2.49 after 22 months: $=0.50$ ), indicating a $54 \%$ $(.50-.23] \times 100 / .50)$ reduction in functional ecline among the intervention group.

In the intervention group there were no significant differences before and after intervention regarding the scores on the Self-Care Ability Scale for the Elderly (SASE) ${ }^{1}$ and the Appraisal for Self-Care
Agency (ASA) (7.00) and after intervention: $76.00(7.00)$ : $p=0.950$ ). ASA Md (IQR)): baseline: 87.00 (14.75) and after intervention: $88.00(11.00) ; p=0.801)$. In the control group, no significant differences emerged between baseline and the assessment after intervention. However SASE and ASA showed worse outcome: SASE (Md (IQR)): baseline: 77.0 (10.00) and after intervention: 75.00 (7.00); $p=0.484)$. ASA Md (IQR)): baseline: 89.00 (18.00) and after intervention: $88.00(9.00) ; p=0.783$ ). According to the open-ended question about the experience of the self-care telephone talks, all the participants were satisfied, and the majority experienced a change in their attitude and adjustment towards their self-care in everyday life. Through the self-care talks, how they thought about self-care as well as how they managed their daily life was acknowledged. They received support and encouragement for their self-care action. 
Table 2

Characteristics of the self-management support programmes.

General Information about the self-management support programmes

information

Author, year,

Period and frequency

tervention characteristics

Characteristics intervention

country,

Alp et al. (2007)!

Once a week for 5 weeks (five

interactive sessions of $50 \mathrm{~min}$ )

A self-management program: 'Choices for Better Bone Health' (Based on Bandura's social learning theory and self-efficacy model); designed to help people control their osteoporosis: three essential tasks: physical, psychological and social management. It offers the opportunity to collaborate with health care providers and it provides a context in which patients could support each other. Selfmanagement class: five interactive sessions of $50 \mathrm{~min}$. Content: information about disease (osteoporosis), life-style recommendations (taking medications), education how to manage consequences of disease (changes in social roles, chronic pain and discomfort), advises about referrals to appropriate providers (to improve physical and emotional well-being or manage comorbid conditions), pain management (by therapy and medication) advises about exercises and environment changes (living savely and reducing risk of falls), development of a personal plan.

Coleman et al. (2012)/ 6-week self-management Australia/English program (6 weekly sessions of $2.5 \mathrm{~h}$ each). 'Clinical phase' is 8 weeks: baseline assessment 1 week before the start of the program and a second assessment the week following assessment the week following the completion of the program.

A disease-specific self-management education program (the 'Osteoarthritis of the Knee Self Management Program' (OAK) designed for delivery by health care professionals (nurses,

physiotherapist, occupational therapists using a manual). Theoretical framework: Social Cognitive Theory to enhance participants' self-efficacy and promote long-term changes in behaviour.

Principles and theories of SM are used to promote behavioural change. In particular, exercise and disease coping strategies are promoted. Group setting (12 participants): six weekly sessions of $2.5 \mathrm{~h}$ each (+printed information), holistic approach and addresses multiple aspects of care. Content: osteoarthritis (explanation and implications), SM skills (goal-setting, problem-solving, modelling, positive thinking and improving self-efficacy), medications (types, interactions and current trends), correct use of analgesia (use, therapeutic dosing, types and side effects), pain management strategies (cognitive and pharmacologic), fitness and exercise (strength, flexibility, aerobic and balance), joint protection, nutrition and weight control, fall prevention (balance and proprioception), environmental risks, polypharmacy and coping with negative emotions.

Elzen et al. (2007)/ The Netherlands/ English
Six weekly group sessions (of each $2.5 \mathrm{~h}$ long).
A Chronic Disease Self-Management Program (CDSMP). Based on the self-efficacy theory. Groupsetting (10-13 participants): six weekly sessions of $2.5 \mathrm{~h}$ each (+patient book: "Living a Healthy Life with Chronic Conditions"). All sessions were led by two leaders (the primary investigator (master-level psychologist, $\mathrm{PhD}$ ) and another professional or a peer-leader) and the detailed manual was followed very strictly throughout all the different groups. Content: the programme incorporates strategies to enhance self-efficacy (weekly action-planning and feed
participants modelling behaviour and problem-solving for each other, re-interpretation of participants modelling behaviour and problem-solving for each other, re-interpretation of symptoms, group problem solving and individual decision-making); exercise; cognitive symptommanagement techniques; information on nutrition; fatigue-management; use of medication;

managing emotions; communication; problem solving and decision-making. control group

Control subjects were instructed

to maintain their sedentary

ifestyle. Compliance checked

weekly by telephone.

Control group had a 6-month waiting period before entering the OAK program.

Control group received care-asusual. After the last

measurement, the control group

also received the patient book

that was used in the

intervention. 
information

Author, year,

country,

Period and frequency

Intervention characteristics

language

Ersek et al. (2003)!

United States

English

7 week self-management group intervention (seven 90 -min group sessions).

Friedman et al. (2009)/ 2-year period. Nurse home-visits United States/

English on an average of once a month.

Friedman et al. (2014)/ 2-year period. Nurse home-visits United States/ on an average of once a month. English An unknown proportion of the home visits attempted to
specifically address ADL functioning.
A primary care-affiliated disease self-management health promotion nurse intervention. Homevisits by trained nurses (Using the PRECEDE health education planning model, several disease management protocols and handbooks for acute and chronic illness symptom self-care and chronic disease self-management). Content: 1: medication review, disease prevention, health promotion, chronic disease self-care and self-management, and health behaviour change and maintenance. 2 : Many of the components of the nurse intervention included physical activity. 3: Physician-patientfamily-nurse conferences to facilitate communication.

A primary care-affiliated disease self-management health promotion nurse intervention. Homevisits by trained nurses (Using the PRECEDE health education planning model, several disease management protocols and handbooks for acute and chronic illness symptom self-care and chronic disease self-management). Content: 1: medication review, disease prevention, health promotion, chronic disease self-care and self-management, and health behaviour change and maintenance activities. 2: Telephone follow-up after home-visits. Positive effects on patient health and disability status, including ADL's, were anticipated 3: Many of the components of the nurse intervention included physical activity. 3: Physician-patient-family-nurse conferences to facilitate communication. weekly, followed by the final session 2 weeks after session 6 . Content: 1 : presentation and emphasized). 3: Setting and working towards individualized pain management goals incl. problemsolving strategies to overcome obstacles in achieving goak

An usual care + structured self-management programme $(24 \mathrm{~h})$, delivered in a group environment with 6-10 participants, led by an occupational therapist and a social worker. The programme was based on self-management, self-efficacy and group model of service delivery theories and principles. Content: 1: welcome and warm-up exercises, 2: revision of homework, 3: learning an practice sessions (information about the disease, education of (personal) problem solving skills strategies, role play and practice activities) and 4 : homework assignments.
A self-management group intervention (3-8 participants) led by a doctoral-level health
Characteristics intervention

control group

Study participants randomized

to the EB condition received an Education Education Booklet. It contained and pain management. The EB group did not receive: 1 : Individual assistance in developing appropriate pain management goals; 2 : instruction and assistance in the use of problem-solving techniques; 3 : instruction and repeated practice of relaxation and pain coping skills; 4: group interaction and support.

Control group did not recieve the intervention (care as usual).

Control group recieved care as usual of all types (hospital,

nursing home, home care, and ambulatory).

Control group received 'usua care': 1: one-to-one case management; 2 : interview in client's home by service

coordinator to discuss service needs and to jointly develo service plan; 3 : visual assessment at low-vision clinic by optometrists and orthoptists 4: referral to internal and external service providers. 
A multi-component disability prevention and disease self-management programme led by a geriatric nurse practitioner (GNP). Content: 1: The GNP contacted each intervention partici primary care physician to obtain information about the patient's current health problems and the provider's goals for the patient. 2: A meeting between the participant and the GNP to develop a provider's goals for the patient. 2: A meeting between the participant and the GNP to develop a
targeted health management plan that addressed risk factors for disability if present (inactivity, smoking, alcohol misuse, psychoactive drug use, depression, poor nutrition) and self-management of chronic illness. Risk factors were identified initially from the baseline health assessment at the time of study enrollment. 3: Follow-up visits and phone contacts to monitor participants' progres towards health goals. 4: Peer support by volunteer mentors (senior centre participants trained in a 12 -session health promotion course). Participants were encouraged to do physical activities (home exercises or activities available at the senior centre) and to attend the Chronic Illness Self-

Management Course (7-weeks, $2 \mathrm{~h}$ classes that combined peer support with health promotion information and disease self-management concepts, led by trained lay leaders using a workbook). All participants were given a set of nutrition tip sheets. Some participants were referred to health care professionals.

A multi-component health promotion-disease self-management nurse intervention based on the logic of empowering, teaching and coaching chronically ill to better manage their own health an interact more effectively with health practitioners. Content: 1 : patient education: monthly hom visits to teach (participants and/or their informal caregivers) relevant knowledge and skills on how to conduct disease self-management using the Consumer Self-Care Strategies and Healthwise for life handbooks), 2: individual health promotion coaching: home visits and telephone

communications by nurses (using the PRECEDE health education planning model) to empower individuals to engage in behaviour change, develop and sustain motivation, develop behavioural skills, and participate in community activities, 3: financial incentive for care coordination: additional payment for physician-patient-family-nurse conferences to facilitate communication, to support lifestyle behaviour change and enhance treatment compliance. The nurse used individualized disease management protocols based on the needs of the participants.

A multicomponent health promotion and disease self-management nurse home visit intervention based on the logic of empowering, teaching and coaching chronically ill to better manage their ow health and interact more effectively with health practitioners. Content: 1: patient education: monthly home visits to teach (participants and/or their informal caregivers) relevant knowledge and skills on how to conduct disease self-management using the Consumer Self-Care Strategies and Healthwise forlfe handbooks) 2: Individual health promotion coaching: home visits and tel Healthwise for communications by nurses (using the PRECEDE health education planning model) to empower individuals to engage in behaviour change, develop and sustain motivation, develop behavioural skills, and participate in community activities. 3 : financial incentie for care coordination: additiona payment for physician-patient-family-nurse conferences to facilitate communication, to support lifestyle behaviour change and enhance treatment compliance. The nurse used individualized disease management protocols based on the needs of the participants.

A telephone-based self-care intervention: Content: 1: a first meeting with health professionals (two occupational therapists, one physiotherapist) and 2: additional five self-care telephone calls $( \pm 30 \mathrm{~min})$. The first part consisted of one gathering together with the participants $(n=15)$ and the three health professionals who made the phone calls during the intervention. Purpose: building up relationship between health professionals and participants, handing out materials, teaching knowledge about ageing in general and making appointments. The second part consisted of the five phone calls, which each participant received from their personal professional, for the purpose of enhancing self-care ability and self-care action among older persons. Themes: (1) self-care habits, eating habits an nutrition, and physical activity, (2) health promotion, identity, and self-esteem, (3) roles and relationships, (4) communication, and (5) building meaning. Before ending each conversation, the participants and their personal health professional wrote a plan for the next self-care talk. Every new session would start with an evaluation upon the previous theme.
Participants in the control group were given a tour of the senior centre and a schedule of senior centre activities. They did not meet with the GNP; however they had access to all senior centre activities that were available to the intervention group.

作 the multi-component healt promotion-disease self-

management nurse intervention

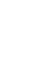

Participants in the control group received their usual care via their Medicare benefits, and they were also compensated with $\$ 10$ per month for completion of health 


\begin{tabular}{|c|c|c|c|}
\hline \multirow{2}{*}{$\begin{array}{l}\text { General } \\
\text { information } \\
\text { Author, year, } \\
\text { country, } \\
\text { language }\end{array}$} & \multicolumn{3}{|c|}{ Information about the self-management support programmes } \\
\hline & Period and frequency & Intervention characteristics & $\begin{array}{l}\text { Characteristics intervention } \\
\text { control group }\end{array}$ \\
\hline $\begin{array}{l}\text { Wetzels et al. (2008)/ } \\
\text { The Netherlands/ } \\
\text { English }\end{array}$ & $\begin{array}{l}6 \text {-month period (preparation } \\
\text { home visit, } 1 \text { home visit by nurse, } \\
1 \text { telephone call to evaluate after } \\
3 \text { months). }\end{array}$ & $\begin{array}{l}\text { A self-management support intervention (performed by a nurse) consisting of education and self- } \\
\text { management of OA symptoms, aimed to change life style behaviour, by improving mobility and } \\
\text { physical functioning. Content: } 1 \text { : Firstly, patients had to prepare for the home visit of the nurse, } \\
\text { using an educational leaflet about osteoarthritis (developed by the Dutch College of General } \\
\text { Practitioners) and a booklet with health-status charts. The patients needed to fill out their level of } \\
\text { exercise, pain-level and their impairments prior to the nurse home visit. } 2 \text { : The charts were } \\
\text { discussed during a } 30 \text {-min nurse home visit. In this home visit patients got insight in their own OA } \\
\text { symptoms. Subsequently, they agreed to try to change one of four life style items (physical exercise, } \\
\text { weight loss, use of a walking aid and how to use over the counter (pain) medication). 3: A follow-up } \\
\text { phone call after approximately } 3 \text { months. In this phone call the nurse evaluated to what extent the } \\
\text { patient had been able to adapt his life style change and subsequently what possibly was necessary } \\
\text { to maintain this change. }\end{array}$ & $\begin{array}{l}\text { Patients in the control group } \\
\text { received only the educational } \\
\text { leaflet about osteoarthritis. }\end{array}$ \\
\hline
\end{tabular}


Bolscher-Niehuis, M.J.T van het, Ouden, M.E.M. den, Vocht, H.M. de, Francke, A.L. Effects of self-management support programmes on activities of daily living of older adults: a systematic review. International Journal of Nursing Studies: 2016, 61(9), 230-247

Fig. 2. Risk of bias summary.

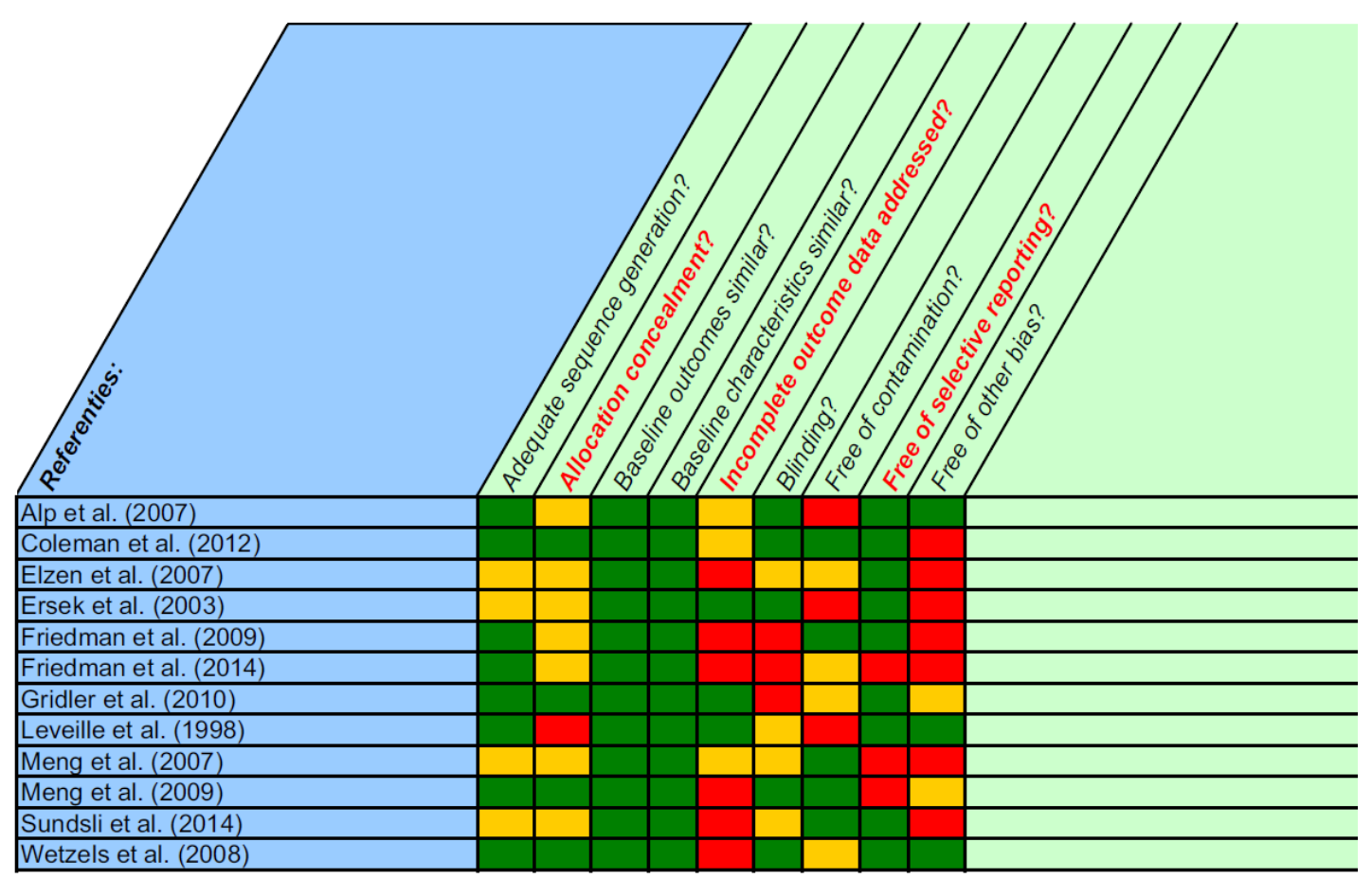

